\title{
LEVELS OF VITAMIN D AND CALCIUM AS RISK FACTORS FOR CHRONIC PERIODONTITIS
}

\author{
Sandy H. S. Hassan, Nayroz Abdel-Fattah Tarrad" and Olfat Gameel Shaker**
}

\begin{abstract}
Objectives: This study was conducted to estimate, compare and correlate the serum and salivary vitamin D3 (VitD3) in form of [25 (OH) D] and calcium (Ca) levels in healthy subjects and chronic periodontitis (C.P) patients.

Subjects and methods: The study included 50 subjects divided into 2 groups: 30 C.P patients and 20 periodontally healthy subjects. Clinical examination was performed for all subjects, salivary and blood samples were collected from all 50 subjects. Salivary and serum VitD3 levels were assessed by ELISA assay, while Ca was measured colouremetrically.

Results : Salivary and serum VitD3 levels were significantly higher in control subjects compared to C.P patients. Salivary Ca level was significantly higher in C.P group than control group but serum Ca level showed insignificance higher level in control group than C.P patients. No significance correlation was observed except for saliva and serum VitD3 levels there was a statistical significance correlation in the control group.

Conclusion: Low salivary and serum VitD3 and high salivary Ca levels are associated with periodontitis, they might be considered as risk factors for periodontal diseases but this association need to be confirmed in more future studies.
\end{abstract}

KEYWORDS: Chronic periodontitis, vitamin D3, calcium, saliva, serum, Egyptian population

\section{INTRODUCTION}

Chromic periodontitis (C.P) is a multifactorial chronic inflammatory disease that may affect more than half of the population, caused by group of specific microorganisms that elicit activation of immune-inflammatory mechanisms which cause several adverse effects on bone and connective tis- sue remodeling resulting in progressive destruction of periodontal ligament and alveolar bone loss ${ }^{(1,2)}$.

Vitamin D3 (VitD3) deficiency is a public health concern as 1 billion people worldwide have VitD3 deficiency ${ }^{[3]}$. Current knowledge about the non hormonal, intracrine, and paracine actions of the active form of VitD3 [25 $(\mathrm{OH}) \mathrm{D}$ ] has shown that it has

* Lecturer in Department of Oral Medicine, Periodontology and Oral Diagnosis, Faculty of Dentistry, Fayoum University ** Professor in Department of Medical Biochemistry, Faculty of Medicine, Cairo University. 
antibacterial effect via increase transcription of antibacterial peptides by cells of monocyte macrophage lineage which can defend against oral pathogens. Also it has anti-inflammatory action as it can inhibit antigen-induced T-cell proliferation and cytokine production. In addition to its well-known role in regulation of calcium $(\mathrm{Ca})$ homeostasis in blood by promoting $\mathrm{Ca}$ absorption in the intestine, reabsorption of $\mathrm{Ca}$ from kidneys and bone formation in order to maintain balanced plasma $\mathrm{Ca}$ concentration and bone mineralization, moreover its stimulation for osteoblasts to enable normal bone growth. ${ }^{[4-6]}$

$\mathrm{Ca}$ and VitD3 are two essential elements in bone mineralization as mentioned in literature there is a tie relationship between both. Chronically low intake of $\mathrm{Ca}$ and VitD3 lead to negative $\mathrm{Ca}$ balance and bone loss as it causes a secondary increase in $\mathrm{Ca}$ removal from bone, consequently decreased general bone mineralization including the alveolar bone. This manifestation may contribute to weakening of the tooth attachment apparatus which is a well recognized symptom of C.P ${ }^{[7]}$.

Despite the causative role of specific bacteria in the onset of C.P, its progression and severity are affected by other recently investigated modifiers as nutrition. Nutrition plays an important role in reducing the risk of developing periodontal diseases basically including vitamins and minerals as their imbalance aggravate destruction of the periodontium. Therefore, the present study was conducted to estimate, compare and correlate the serum and salivary VitD3 and Ca levels in healthy subjects and C.P patients ${ }^{[8]}$.

\section{SUBJECTS \& METHODS}

\section{Study population}

Fifty subjects were included in this study both males and females, age range (23 - 48) years. The subjects were divided into two groups,
Group I (Control Group): 20 periodontally healthy volunteers who served as control subjects.

Group II (Chronic Periodontitis Group): 30 patients suffering from C.P. All subjects had signed an informed written consent form and the study was approved by the research ethics committee, after explaining the study procedures.

\section{Inclusion Criteria}

All participants were free from any systemic diseases according to the modified Cornell Medical Index ${ }^{[9]}$. C.P patients were selected from the Outpatient Clinic, Department of Oral Medicine, Periodontology and Diagnosis, Faculty of Dentistry, Fayoum University. Patients were diagnosed with severe C.P when having a pocket depth (PD) of $\geq 5 \mathrm{~mm}$ and a clinical attachment level (CAL) $\geq 5 \mathrm{~mm}$, according to the Periodontology TAAo, (2000) ${ }^{[10]}$. The control group $(n=20)$ was selected from healthy subjects who attended the restorative dental clinic and had clinically healthy gingiva with $\mathrm{PD} \leq 3 \mathrm{~mm}$, zero plaque index (PI), gingival index (GI) and CAL.

\section{Exclusion Criteria}

(1) pregnant women, (2) subjects taking any type of medication and/or antibiotic therapy during the 3 months before the study, (3) subjects who received periodontal treatment within the past 6 months, and (4) smokers.

\section{Clinical examination}

Clinical examination for all patients was performed including the following periodontal parameters PI, GI, PD and CAL. These measurements were recorded by a single calibrated expert examiner at six sites for all teeth (mesiobuccal, mesiolingual, midbuccal, distobuccal, distolingual and midlingual). PI was assessed by measuring the presence or absence of supragingival biofilm with a sweeping movement of the probe around the surfaces of all teeth ${ }^{[11]}$. Marginal gingival bleeding was recorded 
with GI ${ }^{[12]}$. PD was measured from the free-gingival margin to the base of the periodontal pocket and CAL was measured from the cementoenamel junction to the base of the periodontal pocket. Measurements were rounded to the highest whole millimetre using the Michigan 0 probe with Williams' markings.

\section{Saliva Samples Collection.}

Collection of unstimulated whole saliva was done using standard techniques ${ }^{[13]}$. Samples were obtained by requesting subjects to swallow first, tilt their head forward and expectorate all saliva in tube for $5 \mathrm{~min}$ without swallowing. After collection, saliva samples were centrifuged at $2000 \times \mathrm{g}$ and the supernatants were separated and stored at $-80^{\circ} \mathrm{C}$ until subsequent analysis.

\section{Blood samples collection.}

Two milliliters of blood was collected from the antecubetial vein under aseptic conditions and then transferred into sterile test tube with anticoagulant to prevent coagulation of blood. Serum samples were separated after centrifugation and stored in aliquots at $-70^{\circ} \mathrm{C}$ until further assays.

\section{Method of Vitamin D3 detection}

VitD3 was measured for all patients and controls using Human 25-Dihydroxy vitamin D (25-OH -D) enzyme-linked immuno sorbent assay (ELISA) kit provided by Sunredbio, Shanghai, China. This ELISA kit is based on the principle of double antibody sandwich technique to detect human 25$\mathrm{OH}-\mathrm{D}$. The kit uses a double-antibody sandwich ELISA to assay the level of Human 25-OH-D in samples. 25-OH-D was added to monoclonal antibody enzyme well which is pre-coated with Human 25-OH -D. Incubation was done; then, 25$\mathrm{OH}-\mathrm{D}$ antibodies labeled with biotin was added, and combined with Streptavidin-HRP to form immune complex; then incubation and washing were carried out again to remove the uncombined enzyme. Then chromogen Solution A, B, were added, the color of the liquid was changed into blue. The concentration of the Human Substance 25-OH-D of sample was positively correlated.

\section{Calcium measurement}

The calcium was measured colouremetrically ${ }^{[14]}$.

\section{Statistical Analysis}

Mean and SD values for clinical parameters, levels of $\mathrm{Ca}$ and VitD3 are calculated for all the study groups. Student's t-test was used to compare between C.P and control groups for normal parametric distribution. Pearson's correlation coefficient was used to determine correlations of VitD3 and $\mathrm{Ca}$ levels and also between saliva and serum for each group. P-values that were less than or equal to 0.01 level were considered statistically significant. Statistical analysis was performed using analysis of variance for multiple comparisons of means of the different groups using Tukey Contrasts at 0.01 significance level. All statistical work were done using $\mathrm{R}$ statistical software version 3.3.3, ${ }^{[15]}$ using 'Rcmdr' package ${ }^{[16,17]}$.

\section{RESULTS}

In the control and C.P groups the mean age range was found to be 34.4 and 37.8 years, respectively.

\section{(Table 1)}

Results of Ca levels: The normal salivary $\mathrm{Ca}$ level in humans is $\mathbf{7 . 5 - 8} \mathbf{m g} / \mathbf{d l}$. The study results demonstrated that the salivary Ca level was higher in group II than group I with a mean value of $\mathbf{9 . 4}$ and $7.2 \mathrm{mg} / \mathbf{d l}$ respectively. There was statistically significant difference in the salivary $\mathrm{Ca}$ level between C.P and control group. But for serum $\mathrm{Ca}$ level, the normal level in humans is 9-11 $\mathbf{~ m g / d l}$, mean value for group I was $10.3 \mathbf{m g} / \mathbf{d l}$ while for group II was $10.1 \mathrm{mg} / \mathrm{dl}$, showed no statistically significant difference between both groups. (Table 1, figure 1) 
Results of VitD3 levels: Statistically significant difference was found when comparing mean values of salivary VitD3 levels in the studied groups as group I mean value was $462.7 \mathrm{pg} / \mathrm{ml}$ and for group II was $240.7 \mathrm{pg} / \mathbf{m l}$. The serum mean value for control group was $27.25 \mathrm{pg} / \mathrm{ml}$ but it decreased with statistically significant difference in C.P group to be $15.2 \mathrm{pg} / \mathrm{ml}$ (Table 1, figure 2)

When the correlation of VitD3 level between saliva and serum was done for each of the study groups, there was a statistical significance correlation in the control group but no correlation existed in the C.P group, while there there was no significance correlation between saliva and serum in both groups regarding $\mathrm{Ca}$ levels (Table 2)

As for the correlation between VitD3 and $\mathrm{Ca}$ levels in saliva in each of the included groups, no significance correlation was observed in both groups and the same regarding their correlation in serum levels (Table 2)

TABLE (1): Characteristics of subjects presented as mean values, $( \pm \mathrm{SD})$ and P \& F values

\begin{tabular}{|l|c|c|c|}
\hline & Periodontitis group $(\mathrm{n}=30)$ & Control group $(\mathrm{n}=20)$ & Results of Student's t-test \\
\hline Age & $37.8( \pm 4.6)$ & $34.4( \pm 5.7)$ & \\
\hline Ca level in serum & $10.1 \mathrm{mg} / \mathrm{dl}( \pm 0.29)$ & $10.3 \mathrm{mg} / \mathrm{dl}( \pm 0.6)$ & F value $=2.515 \quad \mathrm{P}<0.12$ \\
\hline Ca level in saliva & $9.4 \mathrm{mg} / \mathrm{dl}( \pm 0.44)$ & $7.2 \mathrm{mg} / \mathrm{dl}( \pm 0.29)$ & F value $=335.3 \quad \mathrm{P}<0.0001^{*}$ \\
\hline VitD3 level in serum & $15.16 \mathrm{pg} / \mathrm{ml}( \pm 1.84)$ & $27.25 \mathrm{pg} / \mathrm{ml}( \pm 3.8)$ & F value $=211.4 \quad \mathrm{P}<0.0001^{*}$ \\
\hline VitD3 level in saliva & $240.7 \mathrm{pg} / \mathrm{ml}(( \pm 20.1)$ & $462.7 \mathrm{pg} / \mathrm{ml}( \pm 27.3)$ & F value $=985.8 \quad \mathrm{P}<0.0001^{*}$ \\
\hline
\end{tabular}

*considered significant

Analysis of variance and mean comparisons at 0.01 level

TABLE (2) Results of Pearson's correlation coefficient for the correlation between VitD3 and Ca levels in saliva and serum in the study groups

\begin{tabular}{|c|c|c|c|}
\hline \multirow{2}{*}{$\begin{array}{c}\text { VitD3 levels in saliva and } \\
\text { serum }\end{array}$} & Group & Correlation coefficients & p-value \\
\cline { 2 - 4 } & VitD3 level in saliva and serum & 0.63937 & 0.0077 \\
\hline \multirow{2}{*}{\begin{tabular}{c} 
Ca levels in saliva and serum \\
\cline { 2 - 4 }
\end{tabular}} & Ca level in saliva and serum & 0.12311 & 0.5169 \\
\cline { 2 - 4 } & Control & 0.34731 & 0.1875 \\
\hline \multirow{2}{*}{\begin{tabular}{c} 
VitD3 \& Ca levels in saliva \\
\cline { 2 - 4 }
\end{tabular}} & VitD3 \& Ca level in saliva & -0.45727 & 0.4641 \\
\hline \multirow{2}{*}{\begin{tabular}{c} 
VitD3 \& Ca levels in serum \\
\cline { 2 - 4 }
\end{tabular}} & VitD3 \& Ca level in serum & -0.23312 & 0.2151 \\
\cline { 2 - 4 } & & 0.25356 & 0.3433 \\
\hline
\end{tabular}




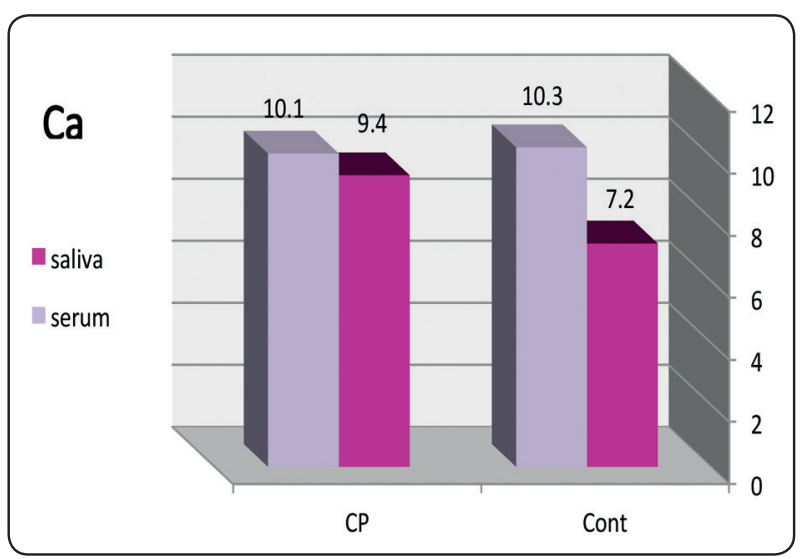

Fig. (1) Showing different means of Ca levels in saliva and serum of the included groups

\section{DISCUSSION}

Low intakes of specific nutrients have been found to be related to periodontal diseases. Thus, nutritional imbalance can impair tissue regeneration, healing and can increase susceptibility to oral infections, so it might affect the development, growth and maintenance of the periodontal tissues. In addition it could be a contributing factor in resistance and virulence of the infective process which determines the extent of the periodontal disease ${ }^{[18,19]}$

$\mathrm{Ca}$ is an essential ion within the human body, maintenance of its concentration is biologically important for the function of tissues. Literature suggests that, salivary $\mathrm{Ca}$ level plays an important role in the initiation of periodontal diseases. Hence VitD3 is a major modulator in Ca homeostasis and immunity plus its antibacterial function, there is a biologic rationale to assume that VitD3 and Ca levels might affect periodontal diseases. Many studies have investigated the effect of a single nutrient on periodontal disease. Although, minerals and vitamins could have interactions between them that affect their homeostasis and functionality. Therefore, the goal of this exploratory study was to investigate whether serum and salivary levels of Ca and VitD3 associated with C.P and to investigate the possibility of interactions between them ${ }^{[20-22]}$.

In the herein investigation, results revealed a statistically significant increase in salivary $\mathrm{Ca}$

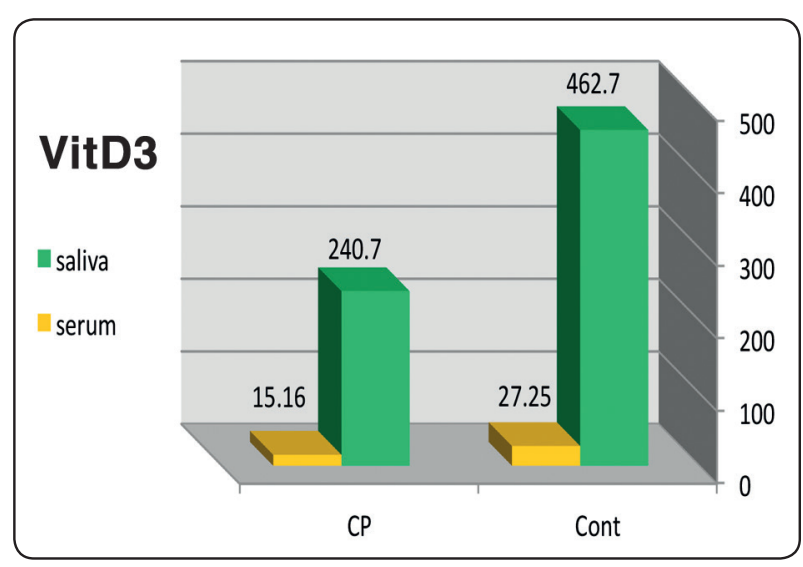

Fig. (2) Showing different means of VitD3 levels in saliva and serum of the included groups

level of C.P patients compared to the healthy control group. These results are consistent with the findings of Sewon et al., 1990, they hypothesized that periodontitis affected patients had a higher remineralization potential. It seems that salivary $\mathrm{Ca}$ due to its high affinity for being readily taken up by plaque is a risk factor for onset of periodontitis ${ }^{[23]}$. In 2010 Khalili \& Biloklytska demonstrated that there is an increase in salivary $\mathrm{Ca}$ concentration in periodontal disease. Moreover, increased $\mathrm{Ca}$ concentration was related to the clinical periodontal status of patients and associated with the severity of the disease ${ }^{[24]}$. In the same line Acharya et al., 2011 and Fyaz et al., 2013, studies results showed that, the subjects in the periodontitis group had significantly higher levels of salivary $\mathrm{Ca}$ than healthy groups ${ }^{[25,26]}$. Recently Patel et al., 2016 and in same year Vasavi et al., investigations concluded that, a positive correlation existed between high salivary Ca content and periodontitis ${ }^{[27,28]}$. On the contrary, in a similar study higher salivary Ca level was related to good dental health and there was no relation to periodontal bone destruction ${ }^{[29]}$.

A study performed by VargheSe et al., 2015 aiming to evaluate the existence of any disturbances in $\mathrm{Ca}$ metabolism and absorption induced by smoking, by quantitatively assessing the variations in the salivary $\mathrm{Ca}$ levels between smokers and non-smokers with periodontitis. The findings of 
their study support the view that, increased salivary $\mathrm{Ca}$ reflecting altered $\mathrm{Ca}$ turnover, fluctuations in dietary $\mathrm{Ca}$ and enhanced mineral dissolving action of osteoclast induced bone resorption among the smokers. It might act as a risk factor for the development and progression of periodontal diseases by hampering the normal structure and function of alveolar bone. They recommended more studies to prove the clinical significance of their findings ${ }^{[30]}$.

Dental plaque is the primary etiological factor responsible for periodontal disease, a polymicrobial biofilms established on tooth surfaces and retained if not removed frequently. Hence saliva is the primary source for mineralization of supragingival plaque and salivary minerals, Ca in particular is taken up by plaque. The rate of this process depends on salivary minerals concentration, if increased it harden plaque more rapidly thus indirectly influencing the level of oral hygiene so contributing in initiation and progression of C.P ${ }^{[28,31]}$. Therefore, the presented results of higher level of salivary Ca in C.P patients than in healthy controls could be attributed to these postulations.

Previous studies found a statistically significant association between low serum $\mathrm{Ca}$ and periodontal disease, suggesting that low serum $\mathrm{Ca}$ may be considered a risk factor for periodontal disease progression ${ }^{[32-34]}$. But the mean total serum $\mathrm{Ca}$ levels observed in our study were within the normal range. Although serum Ca was higher in control group than C.P group however, the difference was statistically insignificant. This difference may be owed to different in number of subjects and differences in the sensitivity of various ELISA kits employed in both studies.

In contrast to the presented data, Vavasi et al., 2016, demonstrated a statistically significant increase in serum $\mathrm{Ca}$ level between C.P and healthy group. They stated that, low dietary intake of $\mathrm{Ca}$ results in bone loss to meet the needs of the body which stimulates secretion of parathyroid hormone causing bone resorption which might be a cause for increased serum Ca level. In periodontitis affected individuals, alveolar bone destruction might be a cause of increased serum Ca level [28]. But recent study in 2017 conducted to correlate between serum Ca level and periodontitis, no significant correlation was observed in their results ${ }^{[35]}$.

Concerning VitD3 serum level, our results demonstrated an inverse association between serum level of VitD3 and C.P as it significantly decreased in group II than group I. These results are in accordance with former studies where, Dietrich et al., 2005, had analyzed 6,700 individuals, found that individuals in the highest quintile of serum VitD3 presented significantly less bleeding as well as lower mean PD , CAL and number of missing teeth. They proposed that VitD3 has anti-inflammatory properties ${ }^{[36]}$. These results were supported by Flavia et al., 2012 as VitD3 showed positive correlation with adiponectin and negative correlation with IL-6 and leptin in addition to inverse relation with level of pathogenic bacteria ${ }^{[37]}$. Moreover, Hiremath et al., 2013 investigation showed that the optimal ranges of serum VitD3 reduce susceptibility to gingivitis as VitD3 has a dose dependent anti-inflammatory effect on gingivitis ${ }^{[38]}$. Furthermore, another conformation to the anti-inflammatory property of VitD3 demonstrated by Andrukhov et al., 2014 as there was significant reduction in secretion of proinflammatory mediators as interleukin (IL) 6, IL8 , monocyte chemotactic protein 1 by $25(\mathrm{OH}) \mathrm{D}$ in periodontal ligament cells after lipopolysaccharides stimulation ${ }^{[39]}$.

A study performed by, Zhan et al,.2014 showed that increase of serum VitD3 was associated with decreased risk of tooth loss suggesting that VitD3 is a protective factor for tooth loss ${ }^{[40]}$. Recently, investigations found significantly lower levels of serum VitD3 in C.P patients compared to controls suggesting that insufficient VitD3 level might be involved in periodontal disease progression ${ }^{[41,42]}$. The previous results support our hypothesis that VitD3 hypovitaminos is a risk factor for periodontal diseases 
Oral epithelial cells are capable of converting inactive VitD3 to the active form of $25(\mathrm{OH}) \mathrm{D}$, which has been shown to induce expression of the antimicrobial peptide LL-37 and other defensins that combat bacterial infection so reduces tissue production of destructive matrix metalloproteinases associated with periodontal disease. Moreover, a study using saliva from healthy subject found that it could inhibit proteolysis of LL-37 by Porphyromonas gingivalis, a bacterium associated with C.P. This mechanism clarify how VitD3 enhances innate immune defenses against periodontal pathogenic bacteria (antibacterial property) ${ }^{[43-45]}$. Another mode of action was found in diabetic model rats with periodontitis as it decreased alveolar bone loss by lowering the expression of nuclear factor kappa beta and the phosphorylation of Janus family kinase [46]. Thus these protective properties confirm our hypothesis again of its potential role in pathogenesis of C.P considering its deficiency as risk factor.

In addition to VitD3 anti-inflammatory, antibacterial, protective property, bone and Ca homeostasis, it is owed immunomodulatory action by its capability to affect the adaptive immune response through selectively stimulating specific T-helper subsets (Th2) that might contribute in resolution of inflammation. Monocyte/macrophages can be induced to secrete molecules that have a strong antibiotic effect. Therefore these mentioned properties can explain to some extent why VitD3 level could has a role in progression of periodontal diseases ${ }^{[47-49]}$.

In contrast to the presented result, Liu et al.,2009 found that plasma VitD3 level was higher among aggressive periodontitis individuals compared with control individuals ${ }^{[50]}$. This difference with the current results may be due to different studied groups as our enrolled patients were C.P affected individuals. Also Antonoglou et al., 2015 stated that there was practically no association between VitD3 level and periodontal health status ${ }^{[51]}$.

Not only the serum level of VitD3 has been shown to be lower in C.P group when compared to healthy control level, but also lower salivary level has been found in C.P group when compared to healthy volunteers. To the best of our knowledge this investigation estimated for the first time the level of VitD3 in saliva. Hence saliva is a complex biological fluid which is an ultra filtrate of plasma, it might be used as sample of body fluid that could be collected more easily, less costly, with minimally trained personals. In addition to its well-known role in induction of periodontal diseases. One might envision that salivary VitD3 level could be used to assess periodontal health ${ }^{[52]}$.

Regarding interaction between $\mathrm{Ca}$ and VitD3 in C.P patients, limited to our results no interaction was demonstrated as our result didn't show significance correlation between their levels neither in serum nor saliva.

Conclusively, our findings corroborate the hypothesis that high salivary $\mathrm{Ca}$ level might aggravate C.P initiation and progression however we didn't find significant relation between serum $\mathrm{Ca}$ level and C.P. In addition lower serum and salivary VitD3 levels in C.P group were observed suggesting its involvement in progression of periodontal diseases. Consequently they could be considered as risk factors, their estimation aid in diagnosis of C.P and improvement of the treatment modality applied. Although more investigations are required to confirm our first trial to asses salivary VitD3 level in C.P patients.

\section{REFERENCES}

1. Hinrichs JE, Novak MJ. : Classfication of Diseases and Conditions Affecting the Periodontium. In, Carranza FA(ed). Carranza's Clinical Peridntology, 11tedition. New Delhi,Reed Elsevier India Private Limited,;41, 2012

2. Genco RJ, Borgnakke WS. Risk factors for periodontal disease. Periodontol 2000.;62:59-94,2013

3. Palacios C, Gonzalez L. :Is vitamin D deficiency a major global public health problem? J Steroid Biochem Mol Biol.;144 Pt:138-45, 2014

4. Amy E. Millen, Kathleen M. Hovey, Michael J. LaMonte,Mya Swanson, Christopher A. Andrews, Melissa A. Kluczynski, et al.: Plasma 25 hydroxy vitamin D concentrations and periodontal disease in postmenopausal women. J Periodontol.; 84: 1243-56, 2013 
5. Vieth R.: Vitamin D toxicity, policy, and science. J Bone Miner Res.;22, 64-68,2007

6. Liu $\mathrm{PT}^{1}$, Stenger S, Li H, Wenzel L, Tan BH, Krutzik SR, Ochoa MT, Schauber J, Wu K, Meinken C, Kamen DL, Wagner M, Bals R, Steinmeyer A, Zügel U, Gallo RL, Eisenberg D, Hewison M, Hollis BW, Adams JS, Bloom BR, Modlin RL: Toll-like receptor triggering of a vitamin D-mediated human antimicrobial response. Science.;311:1770-1773,2006

7. Miley DD, Garcia MN, Hildebolt CF, Shannon WD, Couture RA, Anderson Spearie CL et al.: Cross sectional study of vitamin $\mathrm{D}$ and calcium supplementation effects on chronic periodontitis. J Periodontol; 80(9):1433-9,2009.

8. Van der Velden, U.; Kuzmanova, D.; Chapple, I.L.C. : Micronutritional approaches to periodontal therapy.J. Clin. Periodontol;142-158,2011

9. Abramson JH. :The cornell medical index as an epidemiological tool. Am J Public Health Nations Health;56:287-98,1996

10. Periodontology TAAo.: "Parameter on chronic periodontitis with slight to moderate loss of periodontal support. American Academy of Periodontology," J Periodontol; 71: 853-855,2000.

11. Silness J, Loe H. :Periodontal disease in pregnancy. II. Correlation between oral hygiene and periodontal condition.ActaOdontolScand; 22: 121-35,1964

12. Löe H. : The Gingival Index, the Plaque Index and the Retention Index Systems.J Periodontol; 38: 610-6,1967

13. M. Navazesh, :Methods for collecting saliva,"Annals of the New York Academy of Sciences;.694:.72-77,1993.

14. E. Melvin Gindler, Ph.D. John D. King, M.D. :Rapid Colorimetric Determination of Calcium in Biologic Fluids with Methylthymol Blue Am J Clin Pathol.;, 58: 376-382, 1972

15. R Core Team. R: A language and environment for statistical computing. R Foundation for Statistical Computing, Vienna, Austria, URL https://www.R-project.org/.2017.

16. Fox, J.: The R Commander: A Basic Statistics Graphical User Interface to R. Journal of Statistical Software, 14(9): $1-42,2005$.

17. Fox, J. and Bouchet-Valat, M. Rcmdr: R Commander. R package version 2.3-1, 2016.

18. Schifferle RE.: Periodontal disease and nutrition: separating the evidence from current fads.Periodontol 2000; 50:78-89,2009

19. Alshouibi EN, Kaye EK, Cabral HJet al.:VitaminDand periodontal health in older men.JDentRes ;92,689-693,2013
20. Sewón LA, Karjalainen S, Söderling EE, Lapinleimu H, Simell O. : Associations between salivary calcium and oral health. J Clin Periodontol. ;25:915-19,1998

21. MM Khan, Joan P Desborough.: Calcium homeostasis. Update in Anaesthesia. Reproduced from the Bulletin of the Royal College of Anaesthetists 2011.

22. Christakos S, Dhawan P, Porta A et al.: Vitamin D and intestinal calcium absorption. MolCellEndocrinol; 347:25-29, 2011

23. Sewon L, Soderling E, Karjalainen S:. Comparative study on mineralization related intra oral parameters in periodontitis affected and perioodontitis free adults. Scand J Dent Res ;;98:305-12,1990

24. Khalili J, Biloklytska HF.: Salivary calcium: A risk indicator in periodontal disease. Clin Chem Lab Med;48:1361-2,2010

25. Acharya A, Kharadi UA, Dhavale R, Deshmukh VL, Sontakke AN.: High salivary calcium level associated with periodontal disease in Indian subjects - A pilot study. Oral Health Prev Dent ;9:195-200,2011

26. Fyaz M, Ramesh A, Ramalingam K, Thomas B, Shetty S, Prakash P. :Association of salivary calcium, phosphate, $\mathrm{pH}$ and flow rate on oral health: A study on 90 subjects. J Indian Soc Periodontol.;17:454-60,2013

27. Patel RM, Varma S, Suragimath G, Zope S: Estimation and Comparison of Salivary Calcium, Phosphorous, AlkalinePhosphatase and $\mathrm{pH}$ Levels in Periodontal Health and Disease: A Cross sectional Biochemical Study J Clin Diagn Res.;10(7):58-61,2016

28. Neeli Vasavi, Ashank Mishra, Krishnajaneya Reddy :Estimation and Comparison of Serum and Salivary Calcium Levels in Periodontitis Patients and Healthy $\mathrm{J}$ Period. Pract. ; 1 : 12-15,2016

29. Sewon L, Makela M.: A study of the possible correlation of high salivary calcium levels with periodontal and dental conditions in young adults.Arch Oral Biol; 35(Suppl):211-12,1990

30. VargheseM, HegdeS, KashyapR, MaiyaAK:.Quantitative Assessment of Calcium Profile in Whole Saliva From Smokers and NonSmokers with Chronic Generalized Periodontitis J Clin Diagn Res.;9(5): 54-7,2015

31. Poff AM, Pearce EI, Larsen MJ, Cutress TW. :Human supragingival in vivo calculus formation in relation to saturation of saliva with respect to calcium phosphates. Arch Oral Biol.;42:93-99,1997 
32. Nishida M, Grossi SG, Dunford RG, Alex W, Trevison M, Genco RJ.: Calcium and the risk for periodontal diseases. J Periodontol;71(7):1057-66,2000

33. Amarasena N, Yoshihara A, Hirotomi T, Takano N, Miyazaki $\mathrm{H}$ :Association between serum calcium and periodontal disease progression in non-institutionalized elderly. Gerodontology. ;25(4):245-50,2008

34. Tanaka K, Miyake Y, Okubo H, Hanioka T, Sasaki S, Miyatake N, Arakawa M Calcium intake is associated with decreased prevalence of periodontal disease in young Japanese women. Nutr J. 24;13:109,2014

35. Chandak LG, Lohe VK, Bhowate RR, Gandhi KP: Correlation of periodontitis with mandibular radiomorphometric indices, serum calcium and serum estradiol in postmenopausal women: A case-control study Indian J Dent Res. ;28(4):388-394,2017

36. Dietrich T, Nunn M, Dawson-Hughes B, Bischoff-Ferrari HA.: Association between serum concentrations of 25-hydroxyvitamin D and gingival inflammation. Am J Clin Nutr ;82:575-580,2005

37. Flavia R. Teles, Ricardo P. Teles,Lynn Martin, Sigmund S. Socransky, and Anne D. Haffaje: Relationships Among Interleukin-6, Tumor Necrosis Factor-a, Adipokines, Vitamin D, and Chronic Periodontitis J Periodontol; 83:1183-1191,2012

38. Hiremath VP, Rao CB, Naik V, Prasad KV. :Antiinflammatory effect of vitamin $\mathrm{D}$ on gingivitis: a doseresponse randomised control trial. Oral Health Prev Dent;11:61-9,2013

39. Andrukhov O, Andrukhova O, Hulan U, Tang Y, Bantleon HP, Rausch-Fan X: Both 25-hydroxyvitamin-D3 and 1, 25-dihydroxyvitamin-D3 reduces inflammatory response in human periodontal ligament cells. PLoS One. 28;9(2):e90301,2014

40. Zhan Yet al:Prospective study of serum 25-hydroxy vitamin D and tooth loss. J Dent Res 93(7):639-644,2014

41. Abreu OJ, Tatakis DN, Elias-Boneta AR, López Del Valle L, Hernandez R, Pousa MS, Palacios C: Low vitamin D status strongly associated with periodontitis in Puerto RicanadulsBMC Oral Health. 2;16(1):89,2016

42. Markus Laky, Kristina Bertl, Hady Haririan, Oleh Andrukhov1, Rudolf Seemann Ivo Volf Alice Assinger, et al., R: serum levels of 25-hydroxyvitamin D are associated with periodontal disease. Clin Oral Investig.; 21(5):15531558,2017

43. Chaushu S Gutner M, Balter D, Bachrach G.: Saliva enables the antimicrobial activity of LL-37 in the presence of proteases of Porphyromonas gingivalis. Infect Immun.; 77: 5558-5563,2009

44. McMahon L, Schwartz K, Yilmaz O, Brown E, Ryan LK, Diamond G.: Vitamin D-mediated induction of innate immunity in gingival epithelial cells. Infect Immun;79:2250-2256,2011

45. M. Das,: Effect of vitamin D supplementation on cathelicidin, IFN-gamma, IL-4 and Th1/Th2 transcription factors in young healthy females. Eur J Clin Nutr ; 68: 3: 338-43,2014

46. Li H, Xie H, Fu M, Li W, Guo B, Ding Y, Wang Q.: 25-hydroxyvitamin D3 ameliorates periodontitis by modulating the expression of inflammation-associated factors in diabetic mice. Steroids 78(2):115-120,2013

47. Lemire JM, Archer DC, Beck L, Spiegelberg HL : Immunosuppressive actions of 1, 25-dihydroxyvitamin D3: preferentialinhibition of Th1 functions. JNutr $125(6$ Suppl):1704S-1708S,1995.

48. Anand N, Chandrasekaran S, Rajput N. :Vitamin D and periodontal health: Current concepts. J Indian Soc Periodontol. ;17:302-308,2013

49. Stein SH, Livada R, Tipton DA. : Reevaluating the role of vitamin D in the periodontium. JPeriodontal Res.;49:545553,2014

50. Liu K, Meng H, Tang X, Xu L, Zhang L, Chen Z, Shi D, Feng X, Lu R:. Elevated plasma calcifediol is associated with aggressive periodontitis. J Periodontol 80:11141120,2009

51. Antonoglou GN, Knuuttila $M$, Niemelä $\mathrm{O}$, Raunio $\mathrm{T}$, Karttunen R, Vainio O, Hedberg P, Ylöstalo P, Tervonen T. : Low serum level of 1, $25(\mathrm{OH}) 2 \mathrm{D}$ is associated with chronic periodontitis. J Periodont Res;50:274-80,2015

52. Chipper R, Loof A, de Groot J, Harthoorn L, Dransfield E, van Heerde W.: Saliva: Methodology and pretreatment effects. J Chromatogr B Analyt Technol Biomed Life Sci.;847:45-53,2007 